INTERNATIONAL JOURNAL OF RESEARCHES IN BIOSCIENCES, AGRICULTURE AND TECHNOLOGY

(C) VISHWASHANTI MULTIPURPOSE SOCIETY (Global Peace Multipurpose Society) R. No. MH-659/13(N)

www.vmsindia.org

\title{
ONE POT SYNTHESIS OF N-ALKYL BENZIMIDAZOLE, BENZIMIDAZOLIN-2-THIONE AND BENZIMIDAZOLIN -2-ONE CATALYZED BY TETRA BUTYL AMMONIUM BROMIDE UNDER MICROWAVE IRRADIATION.
}

Arvind Tapase

Department of Chemistry, Abasaheb Marathe Arts and New Commerce, Science College, Rajapur (Vikhare-Gothane) Dist. Ratnagiri 416702

Email: arvindtapase@yahoo.com

\begin{abstract}
:
A simple and high yielding one pot method for synthesis of $N$-alkyl Benzimidazole, Benzimidazolin $-2-$ thione and Benzimidazolin -2-one by using tetra butyl ammonium bromide as catalyst. The short reaction time, cleaner reaction and easy work up make this protocol practical and economically attractive.
\end{abstract}

Keywords: Benzimidazole, Benzimidazolin - 2 - thione, Benzimidazolin-2-one, tetra Butyl Ammonium Bromide, Microwave chemistry.

\section{INTRODUCTION}

Microwave heating is totally different from conventional heating. In case of conventional heating, the heat gradient is from the heating device to the medium while in case of microwave heating the heat is dissipated inside the irradiated medium (mass heating) and heat transfers from the medium to outside. Again in case of conventional heating, the heat transfer depends on thermal conductivity, on the temperature difference across the material and on convection currents and therefore the temperature increase is often rather slow. While in microwave heating due to the mass heating effect, much faster temperature increase can be obtained depending on microwave power and the loss factor of the material being irradiated. ${ }^{1}$ The rapid heating of foodstuffs in microwave ovens is routinely used by a significant proportion of mankind. However, people have recognized other potential applications for this method of heating and scientists engaged in a number of disciplines have applied the rapid heating associated with microwave technology to a number of useful processes. These include the preparation of samples for analysis, application to waste treatment, polymer technology, drug release/targeting, ceramics and alkane decomposition. The technique has also found use in a range of decomposition processes including hydrolysis of proteins and peptides. Application to inorganic solid state synthesis has also been shown to have significant advantages. Organic synthesis is an area which can benefit significantly from this technology, with still a large scope of improvement. ${ }^{2}$ Microwave assisted organic synthesis (MAOS) is a fast developing area in synthetic organic chemistry. The basis of this synthetic technique is the empirical observation that some organic reactions proceed much faster and with higher yields under microwave irradiation compared to conventional heating. Although different hypotheses have been proposed to account for the effect of microwave on organic reaction/compounds, the reaction for the dramatic acceleration effect is thought to be instaneous super heating of the reaction medium. Regardless of the exact origin of the microwave effect, it is found to be extremely efficient and applicable to a very broad range of practical synthesis. Utilizing microwave irradiation, several reactions of synthetic importance such as alkylation, condensation, halogenation and oxidation have been reported in literature recently ${ }^{3}$.

Microwave synthesis represents a major break-through in synthetic methodology. A dramatic change in the way chemical synthesis is performed and in the way it is perceived in the scientific community. 
Conventional heating, long known to be inefficient and time-consuming, has been recognized to be creatively limiting as well. Microwave synthesis gives organic chemists more time to expand their scientific creativity, test new theories and develop new processes. Instead of spending hours or even days synthesizing a single compound, chemists can now perform that same reaction in minutes. In concert with rapidly expanding applications, microwave synthesis can be effectively applied to any reaction scheme, creating faster reactions, improving yields, and producing cleaner chemistries $^{4}$.

For long time heterocyclic have constituted one of the largest area of research in organic chemistry. Heterocycles play an important role in biochemical processes and are of interest in biology, pharmacology, microelectronics and optoelectronic material sciences. Benzimidazole is a heterocyclic compound. This bicyclic compound consists of the fusion of benzene and imidazole ${ }^{5}$.

Benzimidazole is five membered benzoheterocyclic compound containing two heteroatoms. Both heteroatoms are nitrogen $(N)$, which are at non-adjacent position. Benzimidazole (aryl and alkyl substituted) have wide variety of reported activities especially, antimicrobial, antitumor, antiviral, antifungal, antioxidant, antiulcer, antiamoebic, antihistaminic, anthelmintic and antihypertensive activity ${ }^{6}$.

The Benzimidazole ring is a structural analogue of the purine bases like adenine and guanine of nucleic acid. Substituted Benzimidazole may be incorporated into the viral nucleic acid by enzymatic process and subsequently can alter the structure and or function of nucleic acid inhibiting viral growth 7 .

Benzimidazoles are among the important heterocyclic compounds found in several natural and non-natural products such as Vitamin $\mathrm{B} 12^{8}$. marine alkaloid kealiquinone, ${ }^{9}$ Benzimidazole nuclesides, ${ }^{10}$ etc. Some of their derivatives are marketed as anti-fungal agents such as
Carbendazim, ${ }^{11}$ anti-helmintic agents such as mebendazole and thiabendazole, ${ }^{12}$ Antipsychotic drug such as Pimozide 13 and other derivatives have been found to possess some interesting bioactivities such as anti-tubercular, ${ }^{14}$ anti-cancer ${ }^{15}$ etc.

\section{MATERIALS AND METHODS \\ General Procedure for N-alkylation of Benzimidazole}

Benzimidazole $(5.0 \mathrm{mmol})$, sodium hydroxide $(20 \mathrm{mmol}), 8 \mathrm{ml}$ of alcohol and catalytic amount of tetra butyl ammonium bromide $(0.50 \mathrm{mmol})$ were taken in a $50 \mathrm{ml}$ beaker, stirred for few second and placed in microwave oven for irradiation at 900 Watt for 30 seconds to get Benzimidazole salt. The mixture was cooled at room temperature. The alkyl halide $(7.5 \mathrm{mmol})$ was added to the resulting mixture and was irradiated in microwave oven at 900 Watt for 55 to 150 seconds to get $N$-alkyl Benzimidazole. The reaction mixture was monitored by TLC. After completion of the alkylation reaction, the content was cooled at room temperature. The reaction mixture was extracted with benzene $(20 \mathrm{ml})$ and washed with $(2 \times 20 \mathrm{ml}) 2 \mathrm{~N}$ hydrochloric acid and water to remove unreacted salt. Then the mixture was dried over anhydrous sodium sulphate. On solvent evaporation solid products were obtained. The crude product was purified by crystallization using ethanol as solvent.

Above procedure is followed for $N$ alkylation of benzimidazolin - 2 - thione and benzimidazolin - 2 - one and microwave irradiation was practiced at same watt and time.

Different $N-$ alkyl Benzimidazole, Benzimidazolin - 2 - thione and Benzimidazolin - 2 - one are given in TableI.

\section{EXPERIMENTAL}

All compounds were characterized by modern spectral and elemental techniques. IR spectra was recorded in $\mathrm{KBr}$ disc on a Perkin Elmer spectrometer for all products ${ }^{1} \mathrm{H}-\mathrm{NMR}$ spectra was recorded on NMR spectrometer in $\mathrm{CDCl}_{3}$ using chloroform as an internal standard. The mass spectra 
was recorded on GCMS-QP 2010 mass spectrometer. All the reagents used were of AR grade and were used without further purification. The reactions were carried out in microwave oven (CE2977 Samsung).

1h. 1-benzyl-1H-benzo[d]imidazole-2(3H)thione

FT-IR (KBr, v cm-1): 3084 (N-H), 2939 (C-H aromatic), 2849 (C-H aliphatic), 1602 (N-H bending), 1494 ((-CH2- bending), 1279 (C$\mathrm{N}), 1200,1066$ (C=S stretching). ${ }^{1} \mathrm{H}$ NMR $\left(\mathrm{CDCl}_{3}\right): \square 7.380-7.067(\mathrm{~m}, 9 \mathrm{H}$, Aromatic), 4.623 (s, 2H), 1.736 (s, 1H) Mass (ES/MS): $\mathrm{m} / \mathrm{z} 240(\mathrm{M}-\mathrm{H})$.

\section{RESULTS AND DISCUSSIONS:}

Under microwave irradiation,

Benzimidazole, Benzimidazolin - thione and Benzimidazolin- 2 one reacts fast with alkyl halide, base, alcohol and tetra butyl ammonium bromide catalyst to give corresponding $\mathrm{N}$-alkyl Benzimidazole, Benzimidazolin - thione and Benzimidazolin- 2 one. The results are summarized in Table I.

$\mathrm{N}-\quad$ alkylation of

Benzimidazole, Benzimidazoline - thione and Benzimidazolin - 2 one.

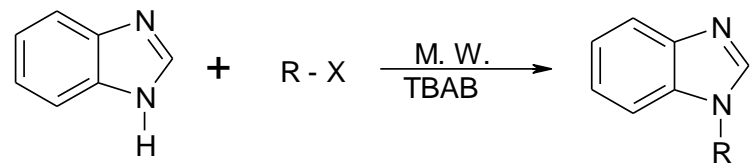

$(1 \mathrm{a}-11)$

$\mathrm{R}=\mathrm{C}_{3} \mathrm{H}_{7}, \mathrm{C}_{4} \mathrm{H}_{9}, \mathrm{C}_{6} \mathrm{H}_{13}$ and $\mathrm{C}_{6} \mathrm{H}_{5} \mathrm{CH}_{2}$

Since the shape and size of the reaction vessel are important factors for the heating of dielectrics in a microwave oven, preferred reaction vessel is a tall beaker of much larger capacity than the volume of the reaction mixture. Superheating of liquids is common under microwave irradiation, thus the strategy of the reactions is to keep the reaction temperature substantially below the boiling point of each compound used for the reaction. Since it is difficult to measure in a household microwave oven, one of the best solution is to repeat an experiment several times increasing slowly power so that vapours do not escape outside the beaker after reaction. The workup procedure is reduced to a treatment with an appropriate solvent (e.g. ethanol) and recrystallization.

The N-alkylation of Benzimidazole, Benzimidazolin - thione and Benzimidazolin- 2 one is carried out under microwave irradiation by simple mixing of Benzimidazole, Benzimidazolin - thione and Benzimidazolin- 2 one with sodium hydroxide, alcohol and tetra butyl ammonium bromide as a catalyst for appropriate time to obtain $\mathrm{N}$-alkyl Benzimidazole, Benzimidazolin - thione and Benzimidazolin- 2 one. The results are summarized in Table-I.

\section{CONCLUSION}

In conclusion, we have developed a simple, efficient and clean methodology for synthesis of $N$ - alkyl Benzimidazole, Benzimidazolin thione and Benzimidazolin- 2 one that occurs under mild conditions using inexpensive reagents and a microwave oven as the irradiation source. Moreover, this synthesis of $N$ - alkyl Benzimidazole, Benzimidazolin - thione and Benzimidazolin- 2 one is superior and faster as compared to conventional methods because the starting material used here is Benzimidazole, Benzimidazolin - thione and Benzimidazolin- 2 one instead of its sodium salt, which makes the synthesis procedure simple, convenient and safe.

\section{ACKNOWLEDGEMENT}

The author is thankful to the Principal, Abasaheb Marathe Arts and New Commerce, Science College, Rajapur Dist. Ratnagiri for providing necessary facilities. 


\section{REFERENCES:}

Desai K. R., Green Chemistry microwave synthesis, first edition, 1, (2005).

Murary M., Charlesworth D., Swires L., Riby P., Cook J. and Chowdhry B. Z., J. Chem. Soc., 90(13), (1999).

Deshayes S., Liagre M., Loupy A., Luche J. L. and Petit A., Tetrahedron, 55, 10851, (1999).

Brittany L Hayes, Microwave Synthesis (C CEM Publishing U.S.A. PP 14, (2002).

Grimmett, M. R. Imidazole and benzimidazole synthesis. Boston: Academic Press (1997).

Shieh W. C., Dell S. and Repic O., Org. Lett., 3, 4279, (2001).

Umare V. D., Ingle V. N. and Wanare R. K., I. J. of Heterocyclic Chem., 17, 253, (2008).

The Merck Index, 13th Edition, Ed. O'Neil M. J., Smith M., Heckelman,
Merck and Co. Inc. NJ. P-1785, (2001).

Nakamura S., Tsuno N., Yamashita M., Kawasaki I., Ohta S. and Ohishi Y., J. C. S. Perkin Trans, 1, 429, (2001).

Migawa M. T., Gardet J. L., Walker J. A., Koszalka G. W., Chamberlian

S. D., Drach J. C. and Townsend L.B., J. Med. Chem., 41, 1242, (1998).

Preston P. N., Chem. Rev., 74, 279, (1974).

Kohler P., Int. J. Parasitol, 31, 336, (2001).

Kyle D., Goehring R. R. and Shao B., WO001, 039775, Chem. Abstr.,135, 33477, (2001).

Kuchkguzel I., Kuchkguzel G., Rollas S. and Kiraz M., Bioorg. Med. Chem. Lett., 11, 1703, (2001).

Islam I., Skibo E. B., Dorr R. T. and Alberts D. S., J. Med. Chem., 34, 2954, (1991). 
Table- I Physical data of the synthesized compounds ( $N$ - alkylation of Benzimidazole, Benzimidazolin thione and Benzimidazolin- 2 one).

\begin{tabular}{|c|c|c|c|c|c|c|c|}
\hline $\begin{array}{l}\text { Sr. } \\
\text { No }\end{array}$ & Compd. & $\mathrm{R}$ & Product & $\begin{array}{c}\text { Watt } \\
\text { W }\end{array}$ & $\begin{array}{l}\text { Time } \\
\text { Sec. }\end{array}$ & $\begin{array}{l}\text { Yield } \\
(\%)\end{array}$ & $\begin{array}{l}\text { M.P/B.P } \\
\cdot \\
\left({ }^{\circ} \mathrm{C}\right)\end{array}$ \\
\hline $1 \mathrm{a}$ & & $\mathrm{C}_{3} \mathrm{H}_{7}$ & & 900 & 110 & 80 & 160 \\
\hline $1 \mathrm{~b}$ & & $\mathrm{C}_{4} \mathrm{H}_{9}$ & & 900 & 150 & 92 & 198 \\
\hline $1 \mathrm{c}$ & & $\mathrm{C}_{6} \mathrm{H}_{13}$ & & 900 & 95 & 90 & 156 \\
\hline $1 \mathrm{~d}$ & & $\mathrm{C}_{6} \mathrm{H}_{5} \mathrm{CH}_{2}$ & & 900 & 55 & 85 & 108 \\
\hline $1 \mathrm{e}$ & & $\mathrm{C}_{3} \mathrm{H}_{7}$ & & 900 & 125 & 82 & 178 \\
\hline 1f & & $\mathrm{C}_{4} \mathrm{H}_{9}$ & & 900 & 130 & 78 & 210 \\
\hline $1 \mathrm{~g}$ & & $\mathrm{C}_{6} \mathrm{H}_{13}$ & & 900 & 110 & 83 & Oil \\
\hline $1 \mathrm{~h}$ & & $\mathrm{C}_{6} \mathrm{H}_{5} \mathrm{CH}_{2}$ & & 900 & 120 & 91 & 120 \\
\hline $1 \mathrm{i}$ & & $\mathrm{C}_{3} \mathrm{H}_{7}$ & & 900 & 115 & 83 & 159 \\
\hline $1 \mathrm{j}$ & & $\mathrm{C}_{4} \mathrm{H}_{9}$ & & 900 & 127 & 86 & 234 \\
\hline $1 \mathrm{k}$ & & $\mathrm{C}_{6} \mathrm{H}_{13}$ & & 900 & 95 & 85 & Oil \\
\hline 11 & & $\mathrm{C}_{6} \mathrm{H}_{5} \mathrm{CH}_{2}$ & & 900 & 80 & 90 & 118 \\
\hline
\end{tabular}

